\title{
Real-time PCR and quantitative culture for monitoring of experimental Aspergillus fumigatus intracranial infection in neutropenic mice
}

\begin{abstract}
Correspondence Juergen Loeffler Loeffler_J@medizin. uni-wuerzburg.de
\end{abstract}

Received 26 November 2010 Accepted 18 March 2011

\author{
C. Oliver Morton, ${ }^{1}$ Karl V. Clemons, ${ }^{2,3,4}$ Jan Springer, ${ }^{5}$ Justus G. Mueller, $^{6}$ \\ Thomas R. Rogers, ${ }^{1}$ David A. Stevens, ${ }^{2,3,4}$ Oliver Kurzai, ${ }^{7}$ \\ Hermann Einsele ${ }^{5}$ and Juergen Loeffler ${ }^{5}$
}
${ }^{1}$ Department of Clinical Microbiology, Sir Patrick Dun Research Laboratory, School of Medicine, Trinity College Dublin, Dublin 8, Ireland
${ }^{2}$ California Institute for Medical Research, San Jose, CA 95128, USA
${ }^{3}$ Department of Medicine, Division of Infectious Diseases, Santa Clara Valley Medical Center, San Jose, CA 95128-2699, USA
${ }^{4}$ Department of Medicine, Division of Infectious Diseases and Geographic Medicine, Stanford University, Stanford, CA 94305, USA
${ }^{5}$ Universität Wuerzburg, Medizinische Klinik \& Poliklinik II, Wuerzburg, Germany
${ }^{6}$ Pathologisches Institut der Universität Wuerzburg, Wuerzburg, Germany
${ }^{7}$ Friedrich-Schiller-Universität Jena, Septomics Research Centre, Leibniz Institute for Natural Products Research and Infection Biology - Hans Knöll Institute, Jena, Germany

\begin{abstract}
The central nervous system (CNS) is the most common site of dissemination during Aspergillus infection. PCR has the potential to facilitate early diagnosis of CNS aspergillosis, which could assist in reducing disease mortality. In two experiments, neutropenic CD-1 male mice were infected intracranially with $5 \times 10^{6}$ conidia of Aspergillus fumigatus. At time points up to $120 \mathrm{~h}$ after infection, mice were euthanized and samples of blood, brain, spinal cord and cerebrospinal fluid (CSF) were taken. The brain fungal burden was determined by quantitative culture, and fungal DNA was detected by quantitative PCR. Plating for $A$. fumigatus from the brain confirmed that all mice had burdens of $\log _{10}>3$ from 4 to $120 \mathrm{~h}$ after infection. A. fumigatus DNA was detected in blood (88\%), brain (96\%), CSF (52\%) and spinal cord (92\%) samples. The brain and spinal cord contained the highest concentrations of fungal DNA. Adapting the extraction protocol to maximize yield from small sample volumes ( $10 \mu \mathrm{l} \mathrm{CSF} \mathrm{or} 200 \mu \mathrm{l} \mathrm{blood}$ ) allowed PCR detection of $A$. fumigatus in infected mice, suggesting the use of CSF and blood as diagnostic clinical samples for CNS aspergillosis.
\end{abstract}

\section{INTRODUCTION}

Invasive aspergillosis is a leading cause of mortality in immunocompromised hosts (Neofytos et al., 2009). Central nervous system (CNS) aspergillosis has been diagnosed with increasing frequency over the past decade (Nadkarni \& Goel, 2005; Schwartz \& Thiel, 2009); parenchymal abscesses represent the majority of these cases, with true meningitis being rare. The majority of cases of CNS aspergillosis are the result of haematogenous spread from primary sites of infection, but neurosurgery and other invasive procedures have been reported as iatrogenic causes

Abbreviations: CNS, central nervous system; CSF, cerebrospinal fluid; GM, galactomannan; ITS, internal transcribed spacer; PAS, periodic acid-Schiff; p.i., post-infection; qPCR, quantitative PCR. of infection (Schwartz \& Thiel, 2009). Analyses of patients with cerebral or disseminated aspergillosis have shown that the mortality rate ranges between 88 and $99 \%$ (Schwartz \& Thiel, 2009), with the survival from onset of symptoms in some patients being as short as 5 days (Pagano et al., 1996).

Murine models play an important role in the evaluation and development of novel treatments and in methods to monitor treatment and diagnose infection (Capilla et al., 2007; Clemons \& Stevens, 2005, 2006). The urgent need for more-effective diagnosis of CNS aspergillosis has been reported (Nadkarni \& Goel, 2005). The main strategies for detecting fungal pathogens include radiological imaging, microscopy and culture methods, as well as antigen detection in infected fluids or tissues (Hope et al., 2005). For CNS aspergillosis, these methods are generally unreliable at 
the early stages of infection (Schwartz \& Thiel, 2009). The detection of galactomannan (GM) in serum samples is widely used in Europe for screening patients at risk for invasive aspergillosis and has shown high specificity and sensitivity in several studies (Mennink-Kersten et al., 2004). However, this assay is affected by the administration of antifungal drugs and cannot be used directly to quantify fungal burden, as the relationship between the fungus and release of GM in the host is poorly understood (MenninkKersten et al., 2004). There is evidence that PCR can detect Aspergillus DNA in patient samples in the absence of GM antigenaemia (Cuenca-Estrella et al., 2009). Early detection of Aspergillus fumigatus in patient cerebrospinal fluid (CSF) has been reported using the Platelia Aspergillus EIA kit for GM (Bio-Rad; Klont et al., 2004) and by nested PCR (Hummel et al., 2006). There is still a need for tools that enable earlier diagnosis of infection and that will allow optimal treatment with the prospect of improving the outcome of CNS aspergillosis. In the current study, we used a murine model of cerebral aspergillosis to examine the potential of real-time PCR as a tool to track dissemination of $A$. fumigatus during infection and to determine the suitability of minute volumes of CSF and blood as diagnostic samples for cerebral aspergillosis.

\section{METHODS}

Organisms and murine model. Neutropenic 6-week-old male CD-1 mice were infected intracranially with $5 \times 10^{6}$ conidia of A. fumigatus (strain 10AF) while under isoflurane anaesthesia, as described previously (Chiller et al., 2002; Singh et al., 2005). The mice were neutropenic throughout the course of the study. Intracranial infection was chosen to ensure the development of cerebral aspergillosis, which would not be guaranteed through an intranasal infection model. Mice were pre-assigned to specific sample time points to exclude bias, with five mice per time point and four uninfected control mice. All animal studies were carried out under a protocol approved by the Institutional Animal Care and Use Committee of the California Institute for Medical Research.

At 4, 8, 24, 72 and 120 h post-infection (p.i.), mice were anaesthetized using isoflurane and exsanguinated for collection of whole blood. CSF samples were collected from the mice after they had been euthanized. In brief, skin and musculature were dissected away to expose the skull, and CSF was sampled from the cisterna magna with a finely drawn glass capillary by direct puncture. CSF samples were dispensed into a screw-cap tube and frozen at $-80{ }^{\circ} \mathrm{C}$. Brain and spinal cord were dissected from the skull following CSF collection.

Quantitative plating. After blood and CSF samples had been taken, the fungal burden in the brain was determined by quantitative culture, as described previously (Chiller et al., 2002; Clemons \& Stevens, 2009; Singh et al., 2005).

DNA extraction. A. fumigatus DNA was extracted from murine CSF $(10 \mu \mathrm{l})$ using a QIAamp DNA Micro kit (Qiagen) and from brain homogenate $(500 \mu \mathrm{l})$, blood $(200 \mu \mathrm{l})$ and spinal cord homogenate $(50 \mu \mathrm{l})$ using a High Pure PCR Template Purification kit (Roche), with the following modifications. CSF with kit buffers ATL and AL (containing carrier RNA) were added to $1.5 \mathrm{ml}$ tubes with proteinase $\mathrm{K}$ [600 milliabsorbance units $(\mathrm{mAU}) \mathrm{ml}^{-1}$ ] and incubated at $56{ }^{\circ} \mathrm{C}$ for $30 \mathrm{~min}$. For brain, blood and spinal cord samples, binding buffer and proteinase $\mathrm{K}\left(600 \mathrm{mAU} \mathrm{ml}^{-1}\right)$ were added (the buffer volumes needed for brain homogenate and blood were twice the amount described in the manual) to the samples and incubated at $70{ }^{\circ} \mathrm{C}$ for $10 \mathrm{~min}$ for blood, $90 \mathrm{~min}$ for spinal cord and overnight for brain homogenate. The different treatment times were chosen due to the relative complexities of the tissues, with brain and spinal cord requiring longer treatment than blood. After proteinase K treatment, all samples were added to tubes of Magna Lyser Green Beads (Roche) and vortex mixed for $90 \mathrm{~s} ; 300 \mu \mathrm{l}$ chloroform : isoamyl alcohol $(24: 1)$ was added and the samples were centrifuged at $10000 \mathrm{~g}$ for $5 \mathrm{~min}$. The supernatants were processed following the manufacturers' instructions in the protocol for isolation of genomic DNA from small volumes of blood (Qiagen) for CSF and in the protocol for isolation of nucleic acids from bacteria and yeasts (Roche) for blood, spinal cord and brain homogenate. Samples were stored at $4{ }^{\circ} \mathrm{C}$ until needed. These DNA extractions followed the principles of fungal DNA extraction recommended by the European Aspergillus PCR Initiative (White et al., 2010), which indicated that bead disruption of samples improved PCR positivity rates.

Quantitative PCR (qPCR). A Taqman probe qPCR assay targeting the internal transcribed spacer 1 (ITS1)/5.8S rRNA gene region (Springer et al., 2011) was used to quantify fungal DNA. In brief, $21 \mu \mathrm{l}$ reactions contained $0.3 \mu \mathrm{M}$ primer Asp fum_F (5'-GCAGTCTGAGTTGATTATCGTAATC-3'), $0.6 \mu \mathrm{M}$ primer Fungi 5.8_R (5'-CAGGGGGCGCAATGTGC-3'), $0.15 \mu \mathrm{M}$ hydrolysis probe ITS-PF (5'-FAM-CAGCGAAATGCGATAAGTAATGTGAATTGCA-TAM-3'), $10 \mu \mathrm{l}$ Taqman Gene Expression Mastermix (Applied Biosystems) and $10 \mu \mathrm{l}$ template DNA. Amplification was carried out in a StepOnePlus machine (Applied Biosystems) with the following conditions: $50{ }^{\circ} \mathrm{C}$ for $2 \mathrm{~min}, 95{ }^{\circ} \mathrm{C}$ for $10 \mathrm{~min}$, and $45 \mathrm{cycles}$ of $95{ }^{\circ} \mathrm{C}$ for $15 \mathrm{~s}, 54{ }^{\circ} \mathrm{C}$ for $30 \mathrm{~s}$ and $72{ }^{\circ} \mathrm{C}$ for $30 \mathrm{~s}$. The PCR primers Asp fum_F and Fungi 5.8_R used in this study have been used previously to quantify A. fumigatus DNA in murine serum samples with a detection limit equivalent to 0.3 A. fumigatus genomes $\mathrm{ml}^{-1}$ (Morton et al., 2010). This assay had a sensitivity of $94 \%$ and specificity of $100 \%$ in spiked clinical samples (detection limit 20 c.f.u. $\mathrm{ml}^{-1}$ in donor blood), with cross-reactions observed with Aspergillus terreus and Aspergillus flavus but not with Candida species (Springer et al., 2011). The number of gene copies was measured by comparing the sample Cq (qPCR threshold cycle) values with a standard curve. The ITS PCR standard was produced by cloning the PCR product using the pGEM-T system (Promega); the resultant plasmid was quantified with a Nanodrop spectrophotometer and used as the target for the standard curve.

GM assay. The presence of GM was detected in brain homogenates using an adaptation of a previously described method for lung samples (Vallor et al., 2008). The amount of GM in supernatants from centrifuged brain homogenates was measured using a Platelia Aspergillus EIA kit (Bio-Rad) in accordance with the manufacturer's instructions.

Histology. Mouse brains for histopathological examination were fixed in $10 \%$ neutral buffered formalin and processed for embedding in paraffin wax (Chiller et al., 2002). Sections were stained with haematoxylin and eosin, periodic acid-Schiff (PAS) and Gomori's silver stain, and examined by light microscopy.

Statistical analysis. Two independent experiments were carried out showing reproducible results and the data presented are from a single representative experiment. Data for qPCR experiments were compared by one-way analysis of variance for each dataset followed by Dunn's multiple comparison post test to examine response over time, and by Mann-Whitney $U$ test to compare tissue types at each time point, using Graphpad Prism (Graphpad Software). c.f.u. burdens were compared using a Mann-Whitney $U$ test. 


\section{RESULTS}

\section{Murine cerebral aspergillosis}

Mice showed clinical signs of progressive CNS disease, with ruffled fur, weight loss and head cant as the primary clinical signs. Some mice showed spinning or occasional paresis prior to euthanasia.

\section{Detection of fungal c.f.u., DNA and GM in brain tissue}

Quantification of A. fumigatus c.f.u. in brain tissue confirmed that all mice had burdens of $\log _{10}>3$ from 4 to $120 \mathrm{~h}$ p.i., which showed a trend towards a gradual decrease over time (Fig. 1). The quantitative data at $4 \mathrm{~h}$ p.i. indicated the initial inoculum in the brain tissue to which later time points could be compared. There was a fluctuation in the amount of fungal DNA detected that was not observed for c.f.u. counts (Fig. 1). Culture of blood and other tissues from uninfected control mice did not yield any fungal growth. The GM data (Fig. 1) indicated that the initial inoculum of conidia did not release GM and that it was only released by actively growing fungi as the infection progressed. The amount of detectable GM showed the largest increase between 24 and $72 \mathrm{~h}$ p.i., which was similar to the PCR data. The uninfected control mice gave no GM signal.

\section{qPCR detection of $A$. fumigatus in CNS samples and blood}

A. fumigatus DNA was detected in $96 \%$ of brain samples, $92 \%$ of spinal cord samples (Fig. 2a), $88 \%$ of blood samples and $52 \%$ of CSF samples (Fig. 2b). A. fumigatus DNA was detected in uninfected control mouse samples (mean \pm SEM values were $5 \pm 5$ gene copies in $200 \mu \mathrm{l}$ blood, $30 \pm 10$ gene copies in $500 \mu \mathrm{l}$ brain homogenate, $38 \pm 21$ gene copies in $10 \mu \mathrm{l} \mathrm{CSF}$ and $383 \pm 211$ gene copies in $50 \mu \mathrm{l}$ spinal cord homogenate). Tissue-specific mean values were subtracted from infected mouse samples before the data were plotted. The mean level of contamination varied considerably among sample types. As an A. fumigatus genome contains 38-90 copies of the ribosomal operon (Herrera et al., 2009), this suggested contamination of approximately $\leqslant$ one conidium in uninfected blood, brain and CSF samples, with potentially ten conidia in uninfected spinal cord samples. These values could be used to establish and apply a cut-off value for a routine diagnostic assay depending on the sample type, as has been suggested for the development of diagnostic PCR assays (Pham et al., 2003). Blood contained the lowest amount of

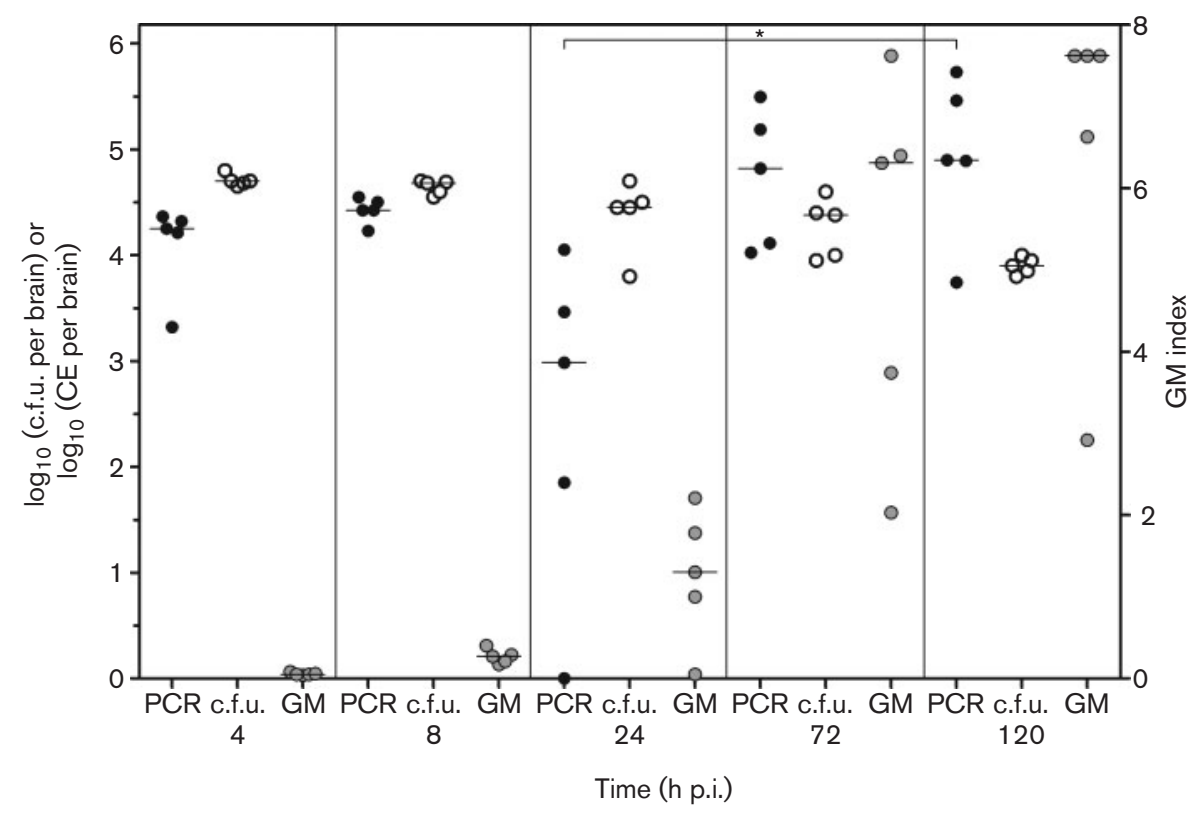

Fig. 1. Comparison of the detection of $A$. fumigatus by PCR, c.f.u. and GM ELISA in the brains of intracranially infected neutropenic mice. There was a trend towards a decrease in c.f.u. counts (c.f.u. at 4 and 8 h p.i. $>$ c.f.u. at 120 h p.i.; $P<0.05$ ) and a fluctuation in the amount of detectable DNA, whereas GM was detectable only after $24 \mathrm{~h}$. Five mice were examined at each time point after inoculation. The qPCR data are expressed as conidial equivalents (CE), which are equivalent to one $A$. fumigatus genome. The graphs show the number of $A$. fumigatus CE $\left(\log _{10}\right.$ scale), c.f.u. $\left(\log _{10}\right.$ scale) and GM index score detected in brain homogenate from each mouse; the median value for each time point (horizontal bar) is shown to highlight trends in the data. PCR samples at each time point were compared by analysis of variance and Dunn's post test. Asterisks indicate where the quantified DNA burden differed significantly between time points $(P<0.05)$. 
(a)

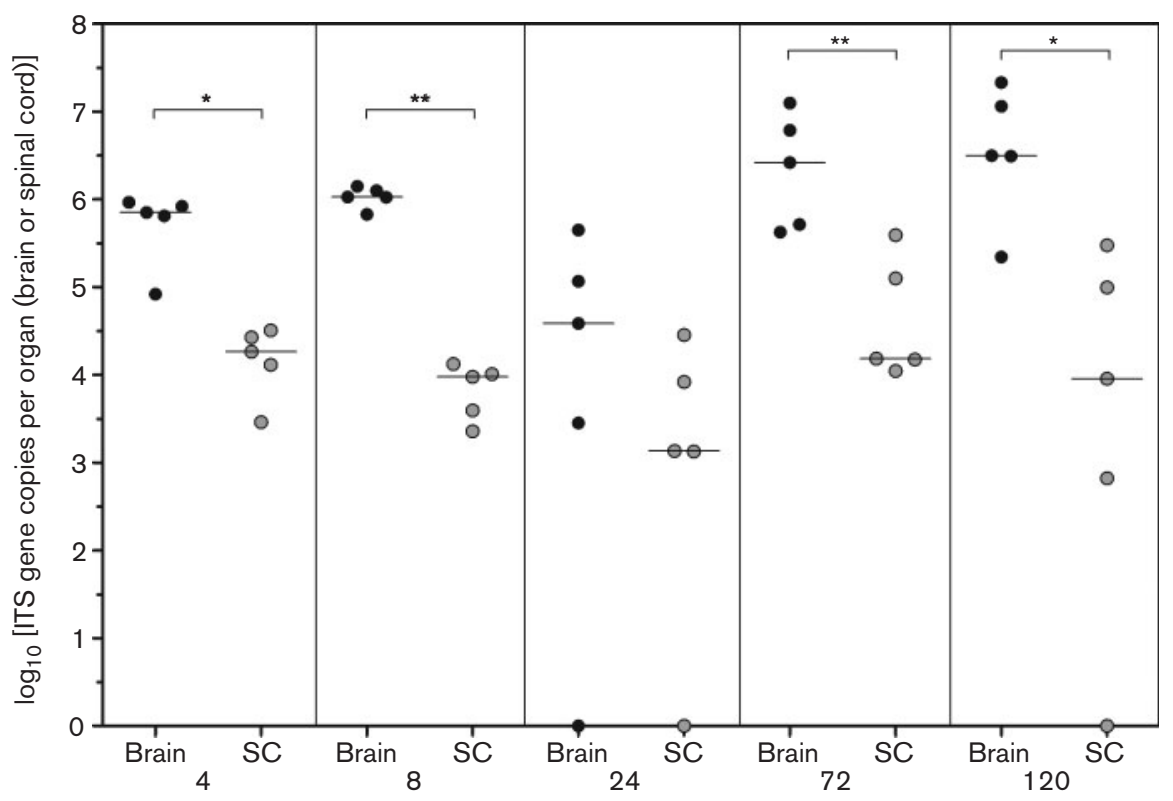

Time (h p.i.)

(b)

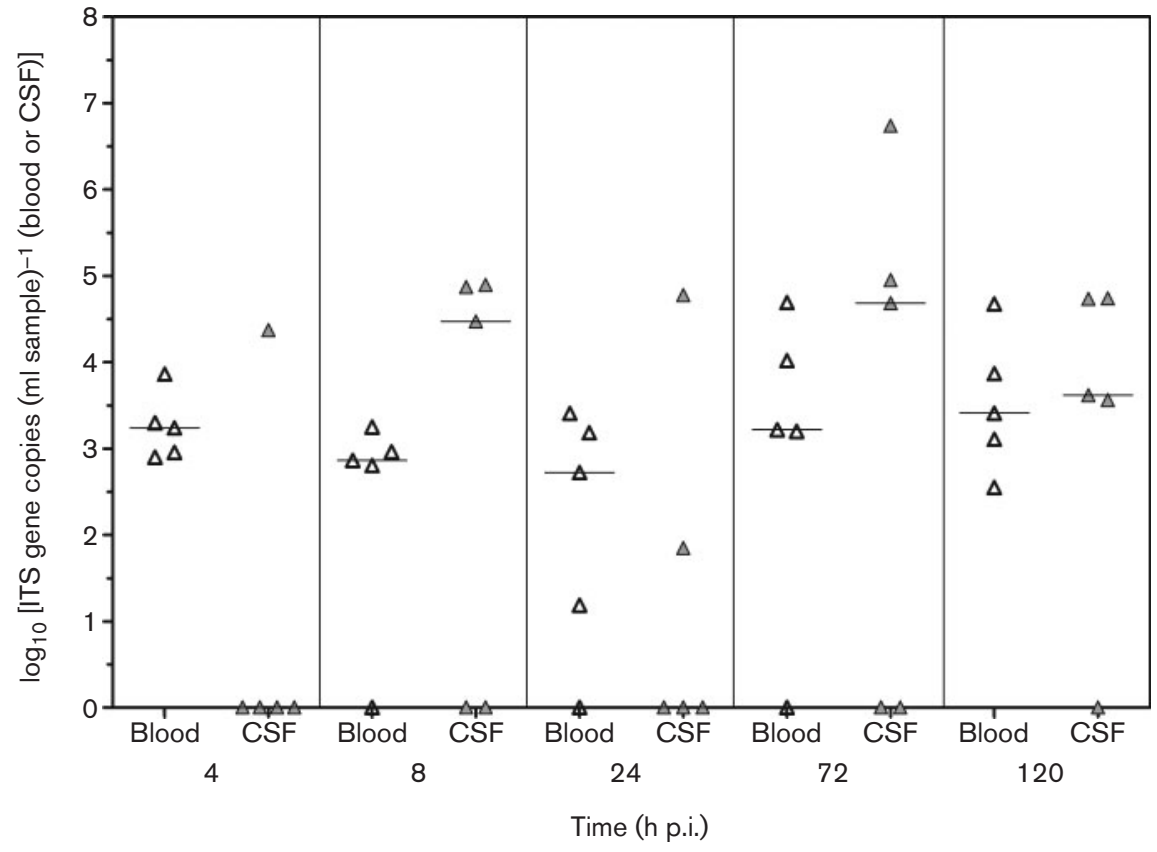

Fig. 2. Detection of $A$. fumigatus DNA by PCR on samples from intracranially infected neutropenic mice. (a) $A$. fumigatus DNA was detected in $96 \%$ of brain samples and $92 \%$ of spinal cord (SC) samples. There was significantly more fungal DNA in brain than in spinal cord, except at 24 h p.i. $(P<0.05)$. (b) A. fumigatus DNA was detected in $88 \%$ of blood samples and $52 \%$ of CSF samples, and the quantified amounts of DNA did not differ significantly between these two tissues. Tissue types at each time point were compared by Mann-Whitney $U$ test. Asterisks indicate where the quantified DNA burden differed significantly between sample types: ${ }^{*}, P<0.05 ;{ }^{*}, P<0.01$.

contaminating DNA, suggesting that the fungal DNA in uninfected CNS samples may have been due to increased sample handling, e.g. brain and spinal cord need to be dissected from the head, leading to possible spore deposition from fur. Contamination is a constant problem with Aspergillus PCR, and some sources are unavoidable 
such as contamination of blood collection tubes (Harrison et al., 2010), reagents (Fredricks et al., 2005; Loeffler et al., 1999) and the host's food (Millon et al., 2010). Establishing a tissue-specific background level is one of the few methods of accounting for this problem.

There was variability in the amount of PCR product detected in specimens at each time point, with brain samples showing the greatest amounts of fungal DNA (Fig. 2). Although the brain samples were larger than the spinal cord samples, it was notable that there was not a significant difference between the sample types at $24 \mathrm{~h}$ p.i. Some of the variability was probably attributable to the response of individual mice and further confounded by the small sample volumes for CSF and spinal cord. As blood and CSF are dynamic liquid systems, it can be expected that the yield of fungal DNA would vary between samples, but it was clear from the data that blood gave more consistent results (Fig. 2b). This could be attributable to sample volume, which is an important consideration when choosing a diagnostic sample.

Each sample type showed a similar trend, with a decrease in DNA levels at $24 \mathrm{~h}$ p.i., followed by an increase at 72 and $120 \mathrm{~h}$ p.i. The variability in the amounts of DNA detected by PCR indicated that this was not significant $(P>0.05)$ for blood, spinal cord and CSF (Fig. 2). However, there was a significant increase in brain fungal DNA between 24 and 120 h p.i. (Fig. 1).

\section{Histology of murine CNS aspergillosis}

The brains of mice that were inoculated intracranially with A. fumigatus showed signs of necrosis in the white brain matter after $72 \mathrm{~h}$ (Fig. 3a). Examination of the necrotic lesions showed focal demyelination and stasis of the capillary blood vessels (Fig. 3b), but there was no cellular reaction besides a mild microglial reaction and no neutrophilic reaction (Fig. 3). Hyphae, showing branching at $\leqslant 45^{\circ}$ angles, which is characteristic of Aspergillus, were only observed at $72 \mathrm{~h}$ p.i. (Fig. 3). There was no detectable communication of necrotic areas with the CSF.

\section{DISCUSSION}

Cerebral aspergillosis in humans has a high rate of mortality (Lin et al., 2001) that could be reduced through improved diagnosis. GM detection in CSF has shown potential for early diagnosis of aspergillosis, with reported detection in one patient 45 days before cultures were positive (Klont et al., 2004). PCR has a similar potential for early diagnosis: a nested PCR assay detected A. fumigatus in the CSF of leukaemic patients with cerebral aspergillosis (Hummel et al., 2006). However, as diagnosis of $A$. fumigatus CNS infection is not optimal, we sought to test the diagnostic potential of a modified $\mathrm{qPCR}$ procedure.

This study showed that a single-round PCR and $10 \mu \mathrm{l}$ sample volume, which is approximately $20 \%$ of the total volume of CSF in mice (Wenk et al., 2004) and would be equivalent to a $20 \mathrm{ml}$ sample from a human, can detect the presence of A. fumigatus DNA in CSF (52\% of samples). Other PCR studies have used larger sample volumes, such as 1.5-2 $\mathrm{ml}$ (Hummel et al., 2006) and $200 \mu \mathrm{l} \mathrm{CSF}$ for spiking experiments (Schabereiter-Gurtner et al., 2007). These data from minute amounts of murine CSF demonstrated that even (a)

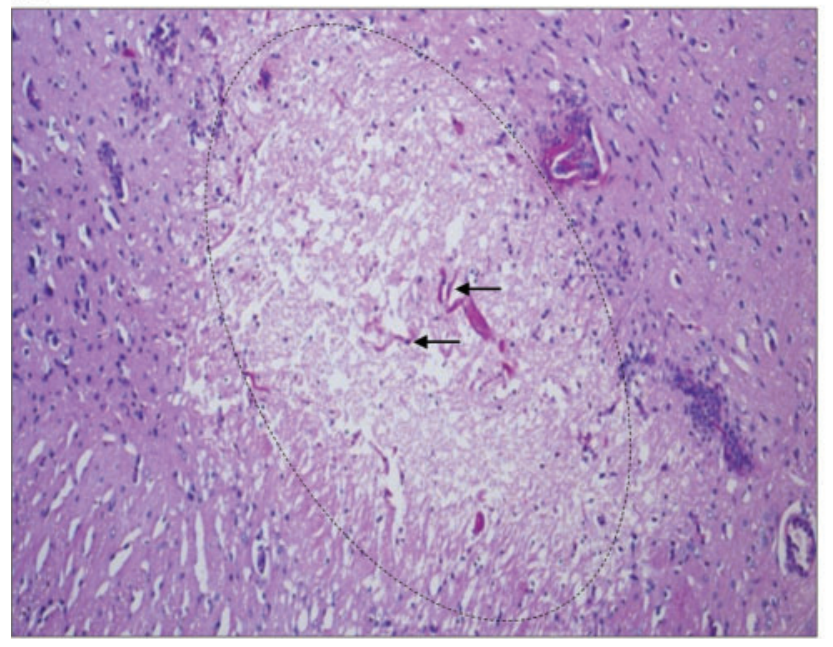

(b)

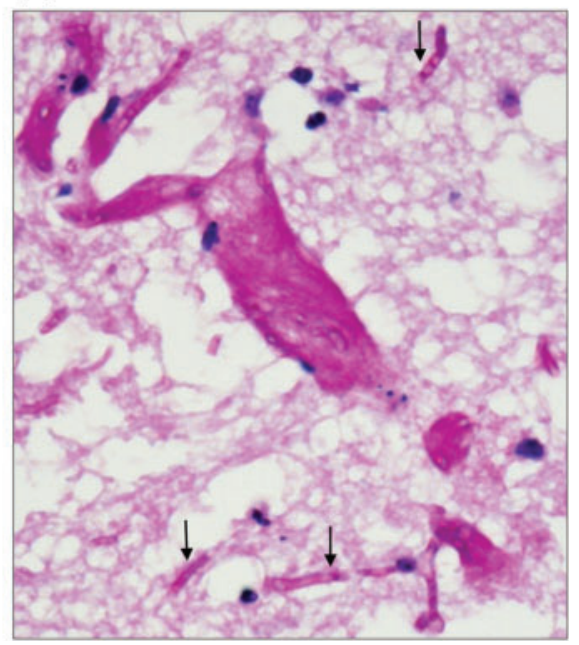

Fig. 3. Histopathological examination of brains from intracranially infected mice. Hyphae were not detected in brain samples until $72 \mathrm{~h}$ p.i. (a) PAS-stained section from the brain of a mouse $72 \mathrm{~h}$ after infection; the circled area shows focal demyelination and stasis of capillary blood vessels. Magnification $\times 100$. (b) Higher-magnification $(\times 630)$ image of the PAS-stained section in (a), showing no cellular reaction besides a mild microglial reaction. There was, however, capillary stasis and focal oedema. The arrows indicate $A$. fumigatus hyphae. 
suboptimal quantities of sample material can yield usable results. Brain and spinal cord are not commonly used as diagnostic samples but were relevant to this model in order to monitor the fate of the A. fumigatus inoculum. Blood and CSF are potential diagnostic samples, with CSF of more interest for cerebral aspergillosis. The data for detection of fungal DNA in CSF (Fig. 2b) suggested that the majority of the inoculum remained in the CNS tissues or was cleared from the CSF, similar to the situation in humans where A. fumigatus is only rarely recovered from the CSF (Kami et al., 1999). CSF samples not yielding a PCR-positive result ( $48 \%$ ) may have been a result of the high turnover of CSF in rodents (Johanson et al., 2008), as rodents can turn over their entire volume of CSF 11 times a day. This would lead to the rapid clearance of conidia from the CSF at the site of infection and, together with the low sample volumes studied, could have created possible false-negative results for some CSF samples. Detection of Aspergillus by qPCR in the blood samples (Fig. 2b) suggested that blood is a route of dissemination for fungal elements, i.e. hyphal fragments or conidia; bead beating to process for extraction of fungal DNA is recommended for the isolation of cellular genomic DNA rather than extracellular DNA (Klingspor \& Loeffler, 2009). In a previous model of cerebral invasive aspergillosis, conidia could be detected in the kidneys at $4 \mathrm{~h}$ after infection, indicating that they are actively cleared from the CSF, most likely via the arachnoid granulations and access into the venous sinuses, a pathway that helps to explain the presence of fungal DNA in blood (Chiller et al., 2002).

PCR results indicated that during the initial $24 \mathrm{~h}$ p.i., there was an initial decline in fungal DNA from the brain, confirmed by comparison with spinal cord at $24 \mathrm{~h}$ p.i. where there was no longer a significant difference between the two tissues (Fig. 2), followed by an increase in fungal DNA in brain and spinal cord at $72 \mathrm{~h}$ p.i., indicating proliferation of the organism in the CNS tissues (Figs 1 and 2a). This apparent disparity between c.f.u. and qPCR data has been observed previously (Bowman et al., 2001; Singh et al., 2005) and has been reviewed elsewhere (Clemons \& Stevens, 2009). It may stem from the fact that c.f.u. counts represent viable fungal elements, whilst PCR measures gene copies that do not have to originate from viable fungus. The difficulty in accurately measuring viable fungal burden is also a product of fungal morphology, as hyphae do not possess a traditional cellular structure: a hyphal tip that would give rise to 1 c.f.u. could contain several nuclei, which would lead to PCR giving a higher estimate of fungal burden (Clemons \& Stevens, 2009). Hyphae were not observed until 72 h p.i. in mouse brain tissue, which supports this hypothesis (Fig. 3). The emergence of hyphae was further supported by the GM measurements, which were negative at 4 and $8 \mathrm{~h}$ p.i. but increased from 24 h p.i. (Fig. 1). This indicated that the brain contained actively growing fungus, which indicates that the PCR and c.f.u. from $24 \mathrm{~h}$ p.i. were derived from hyphae.

Our adaptation of the extraction protocol to maximize yield allowed PCR detection in small sample volumes and different sample types. In this model of cerebral aspergillosis, the qPCR data suggested that a portion of the initial inoculum, both viable and dead fungal elements, was cleared from the brain and CSF into the blood, thus leading to a reduced fungal burden after $24 \mathrm{~h}$. The subsequent increase in fungal DNA in CNS tissues after $72 \mathrm{~h}$ was probably the result of the establishment of an infection through live hyphal growth, which was confirmed by microscopy and GM detection. In the presence of viable fungus, qPCR and GM detection were complementary, and it has been proposed that combining diagnostic tests such as antigen detection assays and $\mathrm{qPCR}$ is a potential diagnostic solution for invasive aspergillosis (Aquino et al., 2007; Botterel et al., 2008).

The capacity to detect fungal DNA from extremely small specimens could be important in a clinical setting where samples for multiple assays are required or when samples are needed from infants. We have provided data that also suggest that CSF may be a useful marker for parenchymal CNS infection by A. fumigatus using real-time PCR.

\section{ACKNOWLEDGEMENTS}

The authors would like to thank Hannes Schloßnagel for preparing the samples for the GM assay. This work was part funded by a European Union Framework 6 grant as part of a project entitled Development of Novel Management Strategies for Invasive Aspergillosis 'MANASP'. This study was presented at the 2010 Interscience Conference on Antimicrobial Agents and Chemotherapy (ICAAC), abstract number M1089.

\section{REFERENCES}

Aquino, V. R., Goldani, L. Z. \& Pasqualotto, A. C. (2007). Update on the contribution of galactomannan for the diagnosis of invasive aspergillosis. Mycopathologia 163, 191-202.

Botterel, F., Farrugia, C., Ichai, P., Costa, J. M., Saliba, F. \& Bretagne, S. (2008). Real-time PCR on the first galactomannan-positive serum sample for diagnosing invasive aspergillosis in liver transplant recipients. Transpl Infect Dis 10, 333-338.

Bowman, J. C., Abruzzo, G. K., Anderson, J. W., Flattery, A. M., Gill, C. J., Pikounis, V. B., Schmatz, D. M., Liberator, P. A. \& Douglas, C. M. (2001). Quantitative PCR assay to measure Aspergillus fumigatus burden in a murine model of disseminated aspergillosis: demonstration of efficacy of caspofungin acetate. Antimicrob Agents Chemother 45, 3474-3481.

Capilla, J., Clemons, K. V. \& Stevens, D. A. (2007). Animal models: an important tool in mycology. Med Mycol 45, 657-684.

Chiller, T. M., Luque, J. C., Sobel, R. A., Farrokhshad, K., Clemons, K. V. \& Stevens, D. A. (2002). Development of a murine model of cerebral aspergillosis. J Infect Dis 186, 574-577.

Clemons, K. V. \& Stevens, D. A. (2005). The contribution of animal models of aspergillosis to understanding pathogenesis, therapy and virulence. Med Mycol 43 (Suppl. 1), S101-S110.

Clemons, K. V. \& Stevens, D. A. (2006). Animal models of Aspergillus infection in preclinical trials, diagnostics and pharmacodynamics: what can we learn from them? Med Mycol 44, S119-S126. 
Clemons, K. V. \& Stevens, D. A. (2009). Conventional or molecular measurement of Aspergillus load. Med Mycol 47 (Suppl. 1), S132-S137.

Cuenca-Estrella, M., Meije, Y., Diaz-Pedroche, C., Gomez-Lopez, A., Buitrago, M. J., Bernal-Martinez, L., Grande, C., Juan, R. S., Lizasoain, M. \& other authors (2009). Value of serial quantification of fungal DNA by a real-time PCR-based technique for early diagnosis of invasive aspergillosis in patients with febrile neutropenia. J Clin Microbiol 47, 379-384.

Fredricks, D. N., Smith, C. \& Meier, A. (2005). Comparison of six DNA extraction methods for recovery of fungal DNA as assessed by quantitative PCR. J Clin Microbiol 43, 5122-5128.

Harrison, E., Stalhberger, T., Whelan, R., Sugrue, M., Wingard, J. R., Alexander, B. D., Follett, S. A., Bowyer, P., Denning, D. W. \& Aspergillus Technology Consortium (AsTeC) (2010). Aspergillus DNA contamination in blood collection tubes. Diagn Microbiol Infect Dis 67, 392-394.

Herrera, M. L., Vallor, A. C., Gelfond, J. A., Patterson, T. F. \& Wickes, B. L. (2009). Strain-dependent variation in 18 S ribosomal DNA copy numbers in Aspergillus fumigatus. J Clin Microbiol 47, 1325-1332.

Hope, W. W., Walsh, T. J. \& Denning, D. W. (2005). Laboratory diagnosis of invasive aspergillosis. Lancet Infect Dis 5, 609-622.

Hummel, M., Spiess, B., Kentouche, K., Niggemann, S., Böhm, C., Reuter, S., Kiehl, M., Mörz, H., Hehlmann, R. \& Buchheidt, D. (2006). Detection of Aspergillus DNA in cerebrospinal fluid from patients with cerebral aspergillosis by a nested PCR assay. J Clin Microbiol 44, 3989-3993.

Johanson, C. E., Duncan, J. A., III, Klinge, P. M., Brinker, T., Stopa, E. G. \& Silverberg, G. D. (2008). Multiplicity of cerebrospinal fluid functions: new challenges in health and disease. Cerebrospinal Fluid Res 5, 10.

Kami, M., Shirouzu, I., Mitani, K., Ogawa, S., Matsumura, T., Kanda, Y., Masumoto, T., Saito, T., Tanaka, Y. \& other authors (1999). Early diagnosis of central nervous system aspergillosis with combination use of cerebral diffusion-weighted echo-planar magnetic resonance image and polymerase chain reaction of cerebrospinal fluid. Intern Med $\mathbf{3 8}$ $45-48$.

Klingspor, L. \& Loeffler, J. (2009). Aspergillus PCR formidable challenges and progress. Med Mycol 47 (Suppl. 1), S241-S247.

Klont, R. R., Mennink-Kersten, M. A. \& Verweij, P. E. (2004). Utility of Aspergillus antigen detection in specimens other than serum specimens. Clin Infect Dis 39, 1467-1474.

Lin, S. J., Schranz, J. \& Teutsch, S. M. (2001). Aspergillosis casefatality rate: systematic review of the literature. Clin Infect Dis 32, $358-366$.

Loeffler, J., Hebart, H., Bialek, R., Hagmeyer, L., Schmidt, D., Serey, F. P., Hartmann, M., Eucker, J. \& Einsele, H. (1999). Contaminations occurring in fungal PCR assays. J Clin Microbiol 37, 1200-1202.

Mennink-Kersten, M. A., Donnelly, J. P. \& Verweij, P. E. (2004). Detection of circulating galactomannan for the diagnosis and management of invasive aspergillosis. Lancet Infect Dis 4, 349-357.

Millon, L., Grenouillet, F., Crouzet, J., Larosa, F., Loewert, S., Bellanger, A. P., Deconinck, E. \& Legrand, F. (2010). False-positive Aspergillus real-time PCR assay due to a nutritional supplement in a bone marrow transplant recipient with GVH disease. Med Mycol 48, 661-664.

Morton, C. O., Loeffler, J., De Luca, A., Frost, S., Kenny, C., Duval, S., Romani, L. \& Rogers, T. R. (2010). Dynamics of extracellular release of Aspergillus fumigatus DNA and galactomannan during growth in blood and serum. J Med Microbiol 59, 408-413.

Nadkarni, T. \& Goel, A. (2005). Aspergilloma of the brain: an overview. J Postgrad Med 51 (Suppl. 1), S37-S41.

Neofytos, D., Horn, D., Anaissie, E., Steinbach, W., Olyaei, A., Fishman, J., Pfaller, M., Chang, C., Webster, K. \& Marr, K. (2009). Epidemiology and outcome of invasive fungal infection in adult hematopoietic stem cell transplant recipients: analysis of multicenter Prospective Antifungal Therapy (PATH) Alliance registry. Clin Infect Dis 48, 265-273.

Pagano, L., Ricci, P., Montillo, M., Cenacchi, A., Nosari, A., Tonso, A., Cudillo, L., Chierichini, A., Savignano, C. \& other authors (1996). Localization of aspergillosis to the central nervous system among patients with acute leukemia: report of 14 cases. Gruppo Italiano Malattie Ematologiche dell'Adulto Infection Program. Clin Infect Dis 23, 628-630.

Pham, A. S., Tarrand, J. J., May, G. S., Lee, M. S., Kontoyiannis, D. P. \& Han, X. Y. (2003). Diagnosis of invasive mold infection by real-time quantitative PCR. Am J Clin Pathol 119, 38-44.

Schabereiter-Gurtner, C., Selitsch, B., Rotter, M. L., Hirschl, A. M. \& Willinger, B. (2007). Development of novel real-time PCR assays for detection and differentiation of eleven medically important Aspergillus and Candida species in clinical specimens. J Clin Microbiol 45, 906-914.

Schwartz, S. \& Thiel, E. (2009). Cerebral aspergillosis: tissue penetration is the key. Med Mycol 47 (Suppl. 1), S387-S393.

Singh, G., Imai, J., Clemons, K. V. \& Stevens, D. A. (2005). Efficacy of caspofungin against central nervous system Aspergillus fumigatus infection in mice determined by TaqMan PCR and CFU methods. Antimicrob Agents Chemother 49, 1369-1376.

Springer, J., Loeffler, J., Heinz, W., Schloßnagel, H., Lehmann, M., Morton, O., Rogers, T. R., Schmitt, C., Frosch, M. \& other authors (2011). Pathogen-specific DNA enrichment does not increase sensitivity of PCR for diagnosis of invasive aspergillosis in neutropenic patients. J Clin Microbiol 49, 1267-1273.

Vallor, A. C., Kirkpatrick, W. R., Najvar, L. K., Bocanegra, R., Kinney, M. C., Fothergill, A. W., Herrera, M. L., Wickes, B. L., Graybill, J. R. \& Patterson, T. F. (2008). Assessment of Aspergillus fumigatus burden in pulmonary tissue of guinea pigs by quantitative PCR, galactomannan enzyme immunoassay, and quantitative culture. Antimicrob Agents Chemother 52, 2593-2598.

Wenk, G. L., McGann-Gramling, K. \& Hauss-Wegrzyniak, B. (2004). The presence of the $a p p_{\text {swe }}$ mutation in mice does not increase the vulnerability of cholinergic basal forebrain neurons to neuroinflammation. Neuroscience 125, 769-776.

White, P. L., Bretagne, S., Klingspor, L., Melchers, W. J., McCulloch, E., Schulz, B., Finnstrom, N., Mengoli, C., Barnes, R. A. \& other authors (2010). Aspergillus PCR: one step closer to standardization. J Clin Microbiol 48, 1231-1240. 